\title{
Experiências de regulaçáo urbana e suas possibilidades: análise a partir do Programa Minha Casa Minha Vida na Regiáo do Grande ABC (Sáo Paulo)
}

Patricia Jesus. Universidade Federal do ABC, São Paulo, Brasil.

Rosana Denaldi. Universidade Federal do ABC, São Paulo, Brasil.

Resumo | Muitas avaliaçóes têm sido feitas ao Programa Minha Casa Minha Vida, sobretudo, quando se referem aos seus efeitos territoriais negativos nas cidades, atribuídos à baixa capacidade reguladora e institucional dos municípios em arbitrar sobre a localização dos empreendimentos habitacionais de um lado, e ao protagonismo das empresas construtoras de outro. Todavia, questiona-se se estes efeitos poderiam ser minimizados em um contexto de aplicação dos instrumentos previstos no Estatuto da Cidade, com o objetivo de reservar áreas adequadas para produção de Habitação de Interesse Social. O artigo analisa a experiência dos municípios da Regiáo do Grande $\mathrm{ABC}$ relativa à aplicação de instrumentos urbanísticos, especialmente às Zonas Especiais de Interesse Social (ZEIS) e sua relação com a produção do PMCMV entre (2009-2014). Conclui-se que a aplicação de tais instrumentos influencia positivamente na operação do Programa, de modo que as localizaçóes mais adequadas de seus produtos, na região, relacionam-se com o histórico de regulação urbana e com a proatividade de suas prefeituras em sua execução.

PALABRAS CLAVE | política habitacional, ordenamento territorial, governo local.

ABstract | Many evaluations have been made to the Programa Minha Casa Minha Vida (PMCMV: My Home My Life Program), especially regarding the negative territorial effects in the cities, on the one hand due to the low capacity of regulation of the municipal government in arbitrating about the location of the housing projects and on the other hand, as a result from the role of construction companies. We question whether those effects could be minimized in a context of application of urban instruments set out by the Statute of Cities that aim to save suitable areas to housing provision. This article analyses the experiences in the $A B C$ Region and its municipalities in applying urban instruments, especially in the Zonas Especiais de Interesse Social (ZEIS) and their relation to the PMCMV results, between 2009 and 2014. The conclusion shows a positive influence in the operation of PMCMV as a consequence of the application of urban instruments, so that the most suitable location of its products in this region are related to the past of urban regulation and to the proactivity of municipalities in its execution.

KEYWORDS | housing policy, spatial planning, local government. 


\section{Introduçáo}

Os problemas relacionados à localização inadequada de conjuntos habitacionais fazem parte da realidade urbana brasileira desde a década de 1960, quando, por meio do Banco Nacional da Habitação (BNH), foi viabilizada, no Brasil, significativa produção habitacional. A produção do BNH segregou as famílias em 'bairros dormitórios' instalados nas franjas das cidades, desprovidos de equipamentos e serviços urbanos. Porém, mais de seis décadas depois, a despeito da comprovação das danosas consequências aos moradores e ao meio ambiente, atualmente, no Brasil, grande parte da produção do Programa Minha Casa Minha Vida em sua faixa prioritária de atendimento - a Faixa I - reproduz essa estratégia.

Lançado em 2009, o Programa Minha Casa Minha Vida foi motivo de otimismo para alguns, pois a justificativa oficial do governo, à época de seu lançamento, foi a deflagração da crise de 2008, iniciada nos EUA e originada no setor imobiliário, e o receio de o Brasil sentir seus efeitos, daí a necessidade de criar um programa anticíclico, ou seja, que operasse no sentido contrário ao da crise.

Considerando que o ambiente macroeconômico brasileiro era, em 2009, bastante favorável, um programa no setor imobiliário seria adequado a este propósito, pois dinamizaria a economia e contribuiria para reduzir o déficit no país de aproximadamente, sete milhóes de unidades habitacionais, segundo dados da Fundação João Pinheiro.

Entretanto muitos manifestaram seu pessimismo e houve várias críticas iniciais a ele: a drenagem de fartos recursos públicos pelo setor privado e igualmente o caráter privatista de sua produção sem controle social; a não aderência ao déficit habitacional na faixa prioritária; o descolamento da arquitetura proposta pelo Programa e as discussóes em curso, no âmbito do Plano Nacional de Habitaçáo, que estava em elaboração quando de seu lançamento; sua interpretaçáo mais como um programa de financiamento e menos como um programa habitacional stricto sensu; a qualidade discutível das habitaçóes; ausência de diálogo com estratégias fundiárias voltadas para ampliar o acesso à terra urbanizada ou voltadas a reservar áreas adequadas à Habitação de Interesse Social e o receio da localização periférica dos empreendimentos produzidos, que poderiam contribuir para agravar a segregação socioespacial no interior das cidades, repetindo o padrão de programas habitacionais pregressos (Arantes \& Fix, 2009; Cardoso, 2013; Ferreira, 2012, 2014; Maricato, 2009; Rolnik, 2010; Rolnik \& Nakano, 2009; dentre outros).

Sabe-se que cabe aos municípios, no âmbito de sua autonomia, legislar sobre o uso e ocupação urbanos e aplicar os instrumentos previstos no Estatuto da Cidade (Lei no 10.257/2001) para fazer cumprir a função social da propriedade urbana, submetendo-a ao interesse coletivo. Entretanto vários estudos apontam que esses instrumentos não estáo sendo efetivamente aplicados (Carvalho \& Rossbach, 2010; Rolnik, 2010; Santos Jr. \& Montandon, 2011).

Articular fomento com regulação urbana, ou seja, condicionar a disponibilização de recursos à aplicaçáo de instrumentos urbanísticos com esta finalidade poderia contribuir para produzir melhores localizaçóes. O desenho inicial do PMCMV, no entanto, não estabeleceu esta condicionante, sendo razoável supor que não o fez 
para alcançar bons resultados quantitativos. Ressalte-se que nem sempre áreas adequadas são delimitadas como Zonas Especiais de Interesse Social (zEIs) e, nesse caso, a produção em zEIS não garante uma boa inserção urbana. Por outro lado, observa-se que vários municípios demarcaram áreas adequadas como ZEIS, mas os empreendimentos do РмСмv foram executados em áreas menos adequadas, e que não haviam sido instituídas como ZEIs, como é o caso do município de Uberlândia, em Minas Gerais. ${ }^{1}$

Outra situação observada é o que ocorreu, por exemplo, em municípios do estado do Rio de Janeiro em que as zeIs não existiam até o advento do PMCMV e foram demarcadas como estratégia de flexibilização de parâmetros de usos a partir da demanda das empresas construtoras para acomodar empreendimentos da Faixa 1 (Rufino, 2015, p. 56; Cardoso, Queiroz, Melo \& Jaenish, 2015, p. 82; Rufino, Uemura, Menegon \& Klintowitz, 2015, p. 124).

Pequeno e Rosa (2015) chamaram atenção para estes casos em que o planejamento e a regulação urbana quando existem, ocorrem a posteriori da produção da moradia, e não a priori, como se observa no ABC. Nesta região, como veremos adiante, as ZEIS coincidem com a produção do PMCMV, principalmente em sua faixa prioritária de atendimento, a Faixa I. Com o intuito de minimizar o problema específico da inadequada localização dos empreendimentos, as alteraçóes do Programa Minha Casa Minha Vida, implementadas em virtude do lançamento de sua segunda fase, ${ }^{2}$ instituíram medidas de incentivo à inserção urbana dos empreendimentos. Mas a autonomia das construtoras sobre a localização deles permaneceu intocada, de modo que, na prática, a problemática realidade pouco se alterou como demonstram estudos e pesquisas, cujo objetivo é avaliá-lo, tanto em sua primeira como em sua segunda fase, sobre os quais fazemos, a seguir, brevíssima síntese.

Ferreira (obra citada) avaliou aspectos de projeto, implantação e inserção urbana dos empreendimentos das Faixas 2 e 3 (circunscritos no denominado segmento econômico das empresas construtoras) em todo o Brasil. Em Cardoso (obra citada), foram publicadas as primeiras análises do PMCMV que indicaram a forte tendência de periferização dos conjuntos habitacionais e as alteraçôes na dinâmica imobiliária em sua decorrência, em cidades dos estados do Paraná, Goiás, Pará, Minas Gerais, Rio de Janeiro e Ceará.

Em Santo Amore, Shimbo e Rufino (2015), foram avaliados todos os aspectos do Programa tal como previu a Chamada MCTi/Cnpq/MCidades no $11 / 2012,{ }^{3}$ e foram tomados como estudos de casos, predominantemente, empreendimentos da Faixa 1

1 Informação verbal concedida em setembro/2016 por Guilherme Augusto Soares da Motta, Diretor de Planejamento de Uberlândia.

2 Medida Provisória no 514 de 01/12/2010 e Decreto no 7.499 de 16/06/2011.

3 Foram avaliados os seguintes aspectos do Programa: qualidade de projetos arquitetônicos e urbanísticos e qualidade construtiva dos empreendimentos produzidos por meio do PмCмv; avaliação da execução e dos resultados do Trabalho Social realizado com as famílias beneficiárias do PMCMV; mecanismos de cadastramento e controle dos beneficiários do PMCMV; impactos sociais e econômicos nas famílias beneficiárias do PMCMV; impactos econômicos regionais ou microrregionais decorrentes da implementação do PMCMV; impactos urbanos e ambientais dos empreendimentos produzidos por meio do РмСмV. 
do Programa, nos estados brasileiros, como Rio de Janeiro, São Paulo, Ceará, Minas Gerais, Rio Grande do Norte e Pará. Dessa obra, destacamos as pesquisas que se dedicaram a avaliar a inserção urbana dos empreendimentos do PMCMV em várias cidades brasileiras: Pequeno e Rosa (2015), Bentes Sobrinha, Silva, Tinoco, Ferreira, Guerra e Silva (2015), Rizek et al. (2015), Rolnik et al. (2015).

A importância de tais pesquisas é inequívoca, principalmente, porque, quando nos dedicamos a estudar o Programa, nos deparamos com o fato de que "por sua característica híbrida - estímulo à moradia social e fortalecimento do mercado privado - o PMCMV não é de fácil acomodação a uma crítica em sentido unilateral" (Bentes Sobrinha et al., 2015, p. 348). Aliás, é essa constatação que justifica seu estudo por diferentes enfoques e perspectivas: modalidades de atendimento, escalas espaciais, agentes promotores, efeitos territoriais nas cidades, localização, dinâmica imobiliária, modelo de financiamento, beneficiários, questóes projetuais etc., pois apenas a análise de variados elementos nos permite compreender sua complexidade, seus limites e suas potencialidades.

Em outras palavras, a constatação bastante presente nas referidas pesquisas de que os empreendimentos do PMCMV estáo inadequadamente inseridos na malha urbana das cidades, ou que eles reforçam o padrão de segregação socioespacial já estabelecidos nessas mesmas cidades diz muito sobre o Programa, mas náo diz tudo sobre os diferentes arranjos em diferentes contextos regionais e sobre as distintas capacidades de regulação dos outros agentes também responsáveis por seu êxito. Neste sentido, o artigo discute aspectos da regulação urbana, seguindo a pista deixada por Ferreira (2014) que atribui às prefeituras municipais a corresponsabilidade pela produção desastrosa do Programa em muitas cidades brasileiras.

Elegeu-se como estudo de caso a Região do Grande ABC, que abriga 2,5 milhôes de habitantes ${ }^{4}$ e é formada pelos municípios de Santo André, São Bernardo do Campo, São Caetano do Sul, Diadema, Mauá, Ribeirão Pires e Rio Grande da Serra, ${ }^{5}$ pois nessa região há expressiva produção do Programa Minha Casa Minha Vida, e em alguns de seus municípios há um histórico de avanços importantes sobre a regulação urbana, desde os anos 1980 (período anterior, portanto, à promulgação do Estatuto da Cidade) e por essas razóes justifica-se como recorte analítico da discussáo aqui proposta.

O objetivo é identificar a localização dos empreendimentos do Programa Minha Casa Minha Vida e das zeis de vazios e analisar se, nesse contexto de uma regiáo que experimentou a regulamentação dos instrumentos do Estatuto da Cidade, obtiveram-se resultados mais positivos.

Primeiramente, discutimos o histórico de aplicação da ZEIS, na região do ABC. Em seguida, apresentamos aspectos gerais do PMCMV e o panorama de sua produçáo na região; por último, examinamos a relação entre essa produção e esse instrumento urbanístico, articulando a análise ao tema da inserção urbana. Ao final, tecemos as consideraçôes finais sobre o conteúdo analisado.

4 Segundo dados do Instituto Brasileiro de Geografia e Estatística (IBGE) para 2010.

5 Todos os municípios do $\mathrm{ABC}$ fazem parte da região metropolitana paulistana. A região está estrategicamente situada entre a capital paulista Sáo Paulo e a cidade de Santos, onde se localiza o maior porto da América Latina. 


\section{As ZEIS de vazios na Regiáo do Grande ABC}

O problema habitacional no $\mathrm{ABC}$ é candente, pois a dinâmica economia resultante da industrialização evoluiu paralelamente à expansão de suas cidades de modo precário, e com ela, surgiram e se expandiram também os loteamentos irregulares e assentamentos precários. O problema é agravado por questóes ambientais, pois grande parcela da população da região habita assentamentos precários e informais que estão inseridos ilegalmente em áreas de mananciais ou de preservação permanente. $^{6}$

As especificidades do meio físico, diferenças relacionadas às condicionantes ambientais, políticas, institucionais e de capacidade de investimento dos municípios do $\mathrm{ABC}$ refletem também nas diferenças de tratamento da questáo habitacional e tipo de regulação urbana a ela vinculada. Desse modo, o tema da aplicação de instrumentos urbanísticos voltados para ampliar o acesso à terra náo foi tratado da mesma forma e período por esse conjunto de municípios.

As Zonas Especiais de Interesse Social podem ser conceituadas como um tipo de zoneamento, estabelecido no âmbito do Plano Diretor ou em legislação específica. No Estatuto da Cidade, o instrumento está previsto na Seção I de seu Capítulo II. Dividem-se em duas grandes categorias: áreas ocupadas por assentamentos precários (favelas, loteamentos irregulares e precários ou cortiços) e áreas vazias. Na década de 1980 as primeiras ZEIS a serem demarcadas foram áreas ocupadas no contexto do reconhecimento desses assentamentos como locais passíveis de ações e intervençôes de urbanização e regularização fundiária, já as zEIs vazias foram demarcadas a partir da década de 1990, com o objetivo de destinar áreas adequadas à produção de habitação para a população de menor renda (Denaldi \& Affonso, 2012). Mas dada a limitação dos entes municipais e estaduais em produzir habitações de interesse social, é a partir do ano de 2009, com o lançamento do PMCMV, que as possibilidades de financiamento para a produção se ampliam significativamente.

Em Santo André, as zeIs de vazio foram criadas em 1991 por meio de legislação específica - Lei no 6.864, de 21/12/1991; em Diadema, em 1994, pelo Plano Diretor Lei Complementar no 25, de 25/01/1994; em São Bernardo do Campo, em 2006, Lei no 5.593, de 05/10/2006; e em Mauá, em 2007 pela Lei no 4.153, 26/03/2007 (Denaldi \& Affonso, 2012). Em Ribeirão Pires e Rio Grande da Serra não há legislação específica que regule o tema, mas o zoneamento está previsto em seus Planos Diretores, e São Caetano do Sul, embora tenha revisado seu Plano Diretor em 2015, não disciplinou zoneamentos especiais de interesse social (CIGABC, 2016, pp.150 e 151).

As ações de definir e demarcar áreas como zEIS, embora sejam um avanço importante é, em realidade, apenas o início do processo. É necessário um conjunto de açôes coordenadas entre os diversos agentes locais e os outros entes federativos para viabilizar de fato açôes de urbanização nas zEIS ocupadas e produção de habitação de interesse social em zeIs de vazios. Nesse último caso, é imprescindível também

6 Área de Proteção aos Mananciais da Bacia Hidrográfica da Represa Billings e Reserva Florestal do Parque Estadual da Serra do Mar. 
atrelar no nível da regulação a demarcação de tais áreas à demanda prioritária por habitação (aquela que recebe rendimento de até três salários mínimos) ${ }^{7}$, sob pena de tais áreas serem facilmente absorvidas para a construção de habitações destinadas a outros estratos de renda, que não o prioritário, pois o conceito de Habitação de Interesse Social não é o mesmo praticado em todos os municípios. Assim, a seguir, discriminamos as zeIs de vazios e como estão determinadas para a produção de Habitação de Interesse Social (HIs), em São André, Diadema, Mauá e São Bernardo do Campo. ${ }^{8}$

Em Santo André, a zeIs B é composta por imóveis não edificados ou subutilizados na Macrozona Urbana, necessários à implantação de programas habitacionais de interesse social, desde que não sejam consideradas áreas ambientalmente sensíveis, e $70 \%$ da área devem ser reservados para produção de HIs; e a ZEIS C são terrenos não edificados e imóveis subutilizados, ou não utilizados, localizados na área do Eixo Tamanduateí, onde haja interesse público em produzir His, e 50\% da área demarcada devem ser reservados para produção de HIs.

Em Diadema, a AEIS 1 são imóveis não edificados e subutilizados, necessários à implantação de Empreendimentos Habitacionais de Interesse Social - EHIs. Em Mauá, a ZEIs 2 são terrenos não edificados em imóveis subutilizados, ou não utilizados, necessários à implantação de programas habitacionais, e 50\% da área demarcada devem ser reservados à produção de His. Por fim, em São Bernardo do Campo, a ZEIs 2 são imóveis não edificados, ou subutilizados, destinados à produção de HIS e HMP, ${ }^{9}$ e 70 \% da área demarcada devem ser reservados para produção de HIs ou de HMP.

$\mathrm{Na}$ Região do Grande ABC, foram demarcadas como zEIS de vazios $6.278 .352,29 \mathrm{~m}^{2}$, sendo $4.637 .019,37 \mathrm{~m}^{2}(76,89 \%)$ reservados para produção de HIS, $1.124 .984,98 \mathrm{~m}^{2}(22,73 \%)$ foram utilizados para esse fim e $3.487 .163,10 \mathrm{~m}^{2}$ $(77,27 \%)$ ainda estão disponíveis para produção de HIs.

A maior proporção de áreas demarcadas como zeIs de vazios pertence a proprietários particulares, somando 4.323.285,08 $\mathrm{m}^{2}$, e o restante, $1.678 .421,02 \mathrm{~m}^{2}$ pertence às diferentes esferas do Poder Público (Municipal, Estadual ou Federal) (Consórcio Intermunicipal do Grande ABC [CIGABC], 2016).

As zeis de vazios podem ser combinadas com a aplicação de outros instrumentos urbanísticos e, em especial, do Parcelamento, Edificação ou Utilização Compulsórios $(\mathrm{PEUC})^{10}$ para potencializar seus efeitos. A imposição do PEUC às ZEIS cria um

O salário mínimo vigente no Brasil em 2016 era R\$ 880,00; em 2017 é R\$ 937,00. A título de referência: us\$1,00 equivale a R\$3,20. Fonte: Banco Central do Brasil em 28/04/2017.

8 As informações sobre os zoneamentos foram extraídas do Capítulo 2 do Diagnóstico Habitacional do Grande ABC. Importa o destaque de que o conceito de Habitação de Interesse Social, neste texto, é o mesmo do estudo Diagnóstico Habitacional do Grande ABC que corresponde aos três salários mínimos vigentes ou à Faixa 1 do PMCMV (CIGABC, 2016).

9 Habitação de Mercado Popular. No Brasil, este segmento compreende o estrato de renda de 3 a 10 salários mínimos.

10 O Parcelamento, Edificação ou Utilização Compulsórios (PEUC) é um instrumento de natureza jurídico-urbanística cujo objetivo é a indução do uso e a ocupação do solo em áreas dotadas de infraestrutura está previsto no $\$ 4^{\circ}$, do Artigo 182 da Constituição Federal e nas Seçôes II, III e IV do Capítulo II do Estatuto da Cidade. São sucedâneos ao PEUC, o IPTU progressivo no tempo e a desapropriação com pagamento mediante títulos da dívida pública 
duplo condicionamento que resulta na obrigação de dar um uso específico: habitação de interesse social, daí a importância da articulação dos dois instrumentos.

TABELA I | ZEIS de vazios na Regiáo do Grande ABC

\begin{tabular}{|c|c|c|c|}
\hline \multirow{2}{*}{ MUNICÍPIO } & \multicolumn{2}{|c|}{ TOTAL DE ZEIS } & \multirow{2}{*}{$\begin{array}{l}\text { \% DO TERRITÓRIO MUNICIPAL } \\
\text { DELIMITADO COMO ZEIS }\end{array}$} \\
\hline & $\mathbf{N}^{\circ}$ & ÁREA $\left(M^{2}\right)$ & \\
\hline Santo André & 46 & $1.489 .839,16$ & 0,85 \\
\hline São Bernardo do Campo & 47 & $2.822 .733,37$ & 0,69 \\
\hline Diadema & 73 & $394.423,37$ & 1,28 \\
\hline Mauá & 34 & $1.259 .710,20$ & 2,03 \\
\hline Ribeirão Pires & 1 & $35.000,00$ & 0,04 \\
\hline Rio Grande da Serra & 3 & $276.646,19$ & 0,76 \\
\hline Região do Grande ABC & 204 & $6.278 .352,29$ & 0,94 \\
\hline
\end{tabular}

FONTE CONSÓRCIO INTERMUNICIPAL DO GRANDE ABC (20I6)

Sua experiência é ainda muito embrionária no Brasil, como nos mostram estudos recentes que tratam de compreender as iniciativas de sua aplicação Denaldi (2015). A pesquisa coordenada por essa autora, por exemplo, mostra que, do universo de 110 municípios brasileiros (capitais estaduais e municípios com população acima de 100 mil habitantes), 25 regulamentaram o instrumento de forma a torná-lo aplicável, e apenas oito aplicaram o instrumento até final de 2015. São eles: Curitiba e Maringá, ${ }^{11}$ no Paraná, Palmas, no Tocantins, Goiânia, em Goiás e São Paulo, Santo André, São Bernardo do Campo e Diadema, no estado de São Paulo.

"Em relação ao IPTU progressivo no tempo, a aplicação foi identificada apenas nos casos de Maringá (PR) e São Bernardo do Campo (SP)” (Denaldi, 2015, p. 15). $\mathrm{O}$ fato de que três dos oito municípios do universo pesquisado estejam no ABC, reforça a importância inequívoca da região para a problemática em discussão.

Ainda assim, a evolução do tema não está se dando sem intercorrências, pois, em Santo André, a prefeitura iniciou a aplicação do instrumento, em 2006, mas a notificação e a averbação dos imóveis foram interrompidas em 2008 com a alternância de governo (Denaldi \& Affonso, 2012).

A prefeitura notificou 45 propriedades para PEUC que correspondem a 1,7 milhão de $\mathrm{m}^{2}$, e 12 desses (cerca de $650 \mathrm{mil} \mathrm{m}^{2}$ ) correspondiam a áreas delimitadas como ZEIs (Denaldi \& Bruno Filho, 2012, p. 105).

Em Diadema, "as primeiras seis notificações visando à utilização compulsória de imóveis com subutilização ocupacional ocorreram apenas em 2007, seis anos após o Estatuto. Apesar do reconhecimento da relevância desse instrumento pela Prefeitura, entraves políticos, jurídicos e administrativos adiaram sua implantação" (Reali \& Alli, 2010, p. 47). Já em São Bernardo do Campo, a implantação tem evoluído como nos informam Souza, Bruno Filho, Bossi e Gazzola (2013). De acordo com os autores, o PEUC foi regulamentado em 2011 (Plano Diretor e Lei Municipal no 6.186, p. 8).

11 Brajato (2015) analisou a experiência do PEUC neste município. 
A partir daí, o processo de identificação de imóveis a serem notificados ocorreu nos anos de 2013 e 2014 obedecendo aos seguintes critérios complementares: capacidade administrativa, priorização por bairro em função de sua proximidade do centro principal e do padrão de urbanização, priorização das zeIs 2 (p. 13). ${ }^{12}$

Partimos, agora, ao exame das principais características do Programa Minha Casa Minha Vida para, em seguida, analisarmos sua produção no ABC.

\section{Aspectos gerais do Programa Minha Casa Minha Vida}

O Programa Minha Casa Minha Vida é o primeiro grande programa de provisão habitacional em nível federal, desde a Ditadura Militar (1964-1985), quando foram construídas, no Brasil, aproximadamente quatro milhóes de habitaçóes pelo extinto Banco Nacional de Habitação (BNH).

A quantidade de recursos públicos por meio de financiamento é bastante significativa em todos os níveis (Faixas 1,2 e 3), ${ }^{13}$ e há significativo subsídio para a faixa prioritária (Faixa 1), proveniente de recursos do Orçamento Geral da União. Em suas duas fases, o Programa tinha como meta a edificação de três milhóes de unidades habitacionais. ${ }^{14}$

A Faixa 1, atualmente é destinada às famílias com rendimento de até $\mathrm{R} \$ 1.600,00^{15}$ e é contemplada pelas seguintes modalidades: Programa Nacional de Habitação Urbana/far (Fundo de Arrendamento Residencial), Programa Nacional de Habitação Popular Entidades/fds (Fundo de Desenvolvimento Social), ${ }^{16}$ Programa Nacional de Habitação Rural e Sub 50 (Oferta pública para municípios com população menor que 50 mil habitantes). Na Fase 1 foram previstas 400.000 uh e na Fase 2 foram previstas 1.200 .000 uh a despeito da correção da proporção entre o déficit e a demanda. A Faixa 2, atualmente, é destinada às famílias com rendimento de até R\$ 3.275,00 e é comtemplada pelas modalidades Programa Nacional de Habitação Urbana/Fgts (Fundo de Garantia por Tempo de Serviço) e Programa Nacional de Habitação Rural/FGTs, cuja fonte de recurso é o Orçamento Geral da União (ogU) e o FGTs. Na Fase 1, foram previstas 400.000 uh e na Fase 2 foram previstas 600.000 uh. A Faixa 3, atualmente, é destinada às famílias com rendimento de até R\$ 5.000,00 e é contemplada pelas modalidades PNHU (FGTS) e PNHR (FGTS), cuja fonte de recurso é o FGTS. Na Fase 1 foram previstas 200.000 uh e na Fase 2 também foram previstas 200.000 uh.

12 Ver adiante na tabela 6 , número e área das zeis de vazios que foram notificadas para PEUC.

13 Na Fase I, as faixas de renda estavam estabelecidas de acordo com o salário mínimo, já na Fase II, elas foram definidas a partir de valores nominais pré-fixados.

14 A Fase I iniciou-se em 2009, no segundo governo de Luís Inácio Lula da Silva, com meta de edificação de um milhão de habitaçôes (Lei Federal no 11.977 de 07/07/09), e a Fase II iniciouse em 2011, no primeiro governo Dilma Rousseff, com meta de edificação de dois milhốes de habitaçốes (Lei Federal no 12.424 de 16/06/2011). Em março de 2016, foi lançada sua Fase III, com meta de construção de mais dois milhôes de unidades habitacionais, entretanto não se sabe se essa nova fase será iniciada (Projeto de Lei 4960/2016).

15 Ver nota 7.

16 Os recursos do Orçamento Geral da União são repassados ao FAR e ao FDs. 
São "duas" as formas de acessar o Programa Minha Casa Minha Vida. Para as Faixas 2 e 3, o Governo Federal repassa recursos diretamente para as construtoras que apresentam projetos às superintendências regionais da Caixa Econômica Federal, que analisam e autorizam o lançamento e a comercialização das moradias. Após o lançamento do empreendimento, os interessados devem procurar a instituição bancária para financiar o imóvel. Já para a Faixa 1 (público alvo prioritário), o Governo Federal garante os recursos e solicita os projetos, que deverão ser apresentados às superintendências regionais da Caixa Econômica Federal pelas construtoras, cooperativas e associaçóes, podendo ser em parceria com o Estado ou prefeituras. No que se refere especificamente às prefeituras, no escopo do Programa há regras e papéis que devem ser cumpridos por elas, contudo, em todo o Brasil, a baixa capacidade técnica e institucional delas as impede de colaborar positivamente em seus resultados. Soma-se a isso, o protagonismo dos agentes privados, em várias etapas de sua operação, e, principalmente, na decisão da localização dos conjuntos (em virtude dos estoques de terras que possuem), conforme aponta Ferreira (2014).

Quanto à tipologia, podem ser construídas casas térreas (unifamiliares) ou edifícios de apartamentos (multifamiliares) de acordo com as características, especificaçóes e custos pré-definidos. Os limites devem obedecer até 500 unidades por módulo ou condomínios segmentados em 300 unidades. As casas devem ter 39,6 $\mathrm{m}^{2}$ e os apartamentos $45,5 \mathrm{~m}^{2}$. Há especificaçôes mínimas sobre piso, revestimento, cobertura, esquadrias, pé-direito, instalaçôes hidráulicas e elétricas, etc. Em regiōes metropolitanas, todavia, em virtude do preço da terra urbanizada, e da necessidade de maior aproveitamento dos terrenos, a maior parte da produção dá-se via tipologia de edifício de apartamentos.

\section{Panorama da produçáo do Programa Minha Casa Minha Vida no ABC}

Foram contratadas, no ABC paulista, 20.131 unidades do Programa Minha Casa Minha Vida, distribuídas em 119 empreendimentos, ${ }^{17}$ nos municípios de São Bernardo do Campo, Santo André, Diadema e Mauá, ${ }^{18}$ segundo dados levantados até o primeiro semestre de 2016. ${ }^{19}$ Deste total, 15.566 estão concluídas, o que representa $77,3 \%$ desta produção, 2.855 encontram-se em obras e 1.710 , na modalidade Entidades, aguardam contratação, pois neste subprograma as obras são contratadas em duas etapas: a primeira referente à compra do terreno e ao projeto, e a segunda refere-se à obra física dos empreendimentos.

17 Todas as unidades contratadas na região do $\mathrm{ABC}$ paulista são do tipo apartamento.

18 Nos municípios de Ribeirão Pires, Rio Grande da Serra e São Caetano do Sul não há unidades contratadas.

19 Os contratos do PMCMV, no ABC, foram realizados entre 2009 e 2014 . Contudo a atualizaçáo dos dados desses contratos foi realizada no âmbito do Diagnóstico Habitacional do Grande ABC, entre os anos de 2014 e 2016, com base em dados da Caixa Econômica Federal e dados das prefeituras de Santo André, Diadema, Mauá e São Bernardo do Campo. Mais informações em Consórcio Intermunicipal do Grande ABC (2016). 
tabela 2 Produçáo do Programa Minha Casa Minha Vida no abc - Faixas 1, 2 e 3 - síntese por município - empreendimentos contratados

\begin{tabular}{|c|c|c|c|c|}
\hline MUNICÍPIO & EMPREENDIMENTOS & $\begin{array}{l}\text { TOTAL DE UH } \\
\text { CONTRATADAS }\end{array}$ & $\begin{array}{l}\text { TOTAL DE UH } \\
\text { CONCLUÍDAS }\end{array}$ & $\begin{array}{c}\text { CONTRATADA I }{ }^{\text {a }} \text { FASE } \\
\text { (TERRENO E PROJETO). } \\
\text { EM CONTRATAÇÃO } \\
\text { 2 }^{\text {a FASE (OBRAS) }}\end{array}$ \\
\hline Santo André & 31 & 4.998 & 3.890 & 910 \\
\hline Diadema & 15 & 3.278 & 2.830 & 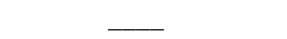 \\
\hline Mauá & 46 & 6.018 & 4.229 & + \\
\hline São Bernardo & 27 & 5.837 & 4.617 & 800 \\
\hline TOTAL & 119 & 20.131 & 15.566 & 1.710 \\
\hline
\end{tabular}

FONTE CONSÓRCIO INTERMUNICIPAL DO GRANDE ABC (20I6)

Tomando-se como análise as modalidades e as faixas de atendimento do Programa, temos o seguinte panorama: na Faixa 1, exclusivamente operada pelo FAR e executada pelas construtoras, foram contratadas 936 unidades em seis empreendimentos, e todas elas foram concluídas. Este número, bastante inferior às outras modalidades da Faixa 1, reforça o argumento de que ela náo é atrativa para as construtoras, sobretudo, em áreas metropolitanas em que o preço da terra urbanizada torna inviável a produçáo dentro do valor financiado pelo Programa. Na modalidade Entidades, operada pelo FDS, foram contratadas 3.516 unidades, das quais apenas 198 foram concluídas, ou seja, apenas 5,63\%, restando ainda 1.710 unidades para serem edificadas. Já as unidades contratadas em vinculação com o Programa de Aceleração do Crescimento (PAC), na intervençáo de tipo Urbanização, somam 2.700, das quais 2.280 foram concluídas, e 420 estão em obras. No caso das modalidades FDS e PAC com recursos FAR, a atuação das prefeituras foi fundamental para a viabilização dos empreendimentos, por meio da doação de terreno nas áreas de zoneamentos especiais, compra parcial de terrenos, complementação da infraestrutura necessária ao empreendimento (CIGABC, 2016).

Assim, toda a Faixa 1 soma os seguintes números: 7.152 unidades contratadas, das quais 3.414 foram concluídas, 2.028 estão em obras, e 1.710 aguardam contratação para a fase de obras. O panorama das Faixas 2 e 3 operadas pelo FGTs é o seguinte: na Faixa 2, foram contratadas 7.784 unidades, das quais 7.393 foram concluídas, ou seja, 95\% de eficácia, e 391 unidades encontram-se em obras. Quanto à Faixa 3, foram contratadas 5.195 unidades, das quais 4.759 foram concluídas, o que representa $91 \%$ de eficácia, e 436 unidades estão em obras.

A análise dos dados para o ABC converge com uma das principais críticas com relação ao Programa, que diz respeito à desproporção entre suas metas de contratação e o déficit habitacional brasileiro (Arantes \& Fix, 2009; Krause, Balbim \& Lima Neto, 2013; Bonduki, 2009; Marques \& Rodrigues, 2013; dentre outros). Ou seja, apesar de o déficit estar concentrado na Faixa 1 do Programa, perceptivelmente há mais contrataçóes nas Faixas 2 e 3. Em sua segunda fase lançada em 2011 as metas foram corrigidas: em maior número para a Faixa 1 e em menor número para as Faixas 2 e 3, no entanto, ao longo dos anos, várias pesquisas apontam a preponderância de contrataçóes na Faixa 2. 
Vejamos que, de acordo com a tabela 3 a seguir, o número de contrataçóes apenas na Faixa 2 (7.784) é maior que o de todas as contrataçóes na Faixa 1, consideradas todas as suas modalidades (7.152).

tabela 3 | Produção do Programa Minha Casa Minha Vida, na Região do Grande ABC - Faixas 1, 2 e 3 - síntese por faixa de renda e modalidade - empreendimentos contratados

\begin{tabular}{|c|c|c|c|c|c|}
\hline FAIXA & MODALIDADE & $\begin{array}{l}\text { EMPREEN- } \\
\text { DIMENTOS }\end{array}$ & $\begin{array}{l}\text { TOTAL DE UH } \\
\text { CONTRATADAS }\end{array}$ & $\begin{array}{l}\text { TOTAL DE UH } \\
\text { CONCLUÍDAS }\end{array}$ & $\begin{array}{c}\text { CONTRATADA } \\
\text { I a FASE (TERRENO } \\
\text { E PROJETO). EM } \\
\text { CONTRATAÇÃo } \\
2^{\text {a }} \text { FASE (OBRAS) }\end{array}$ \\
\hline \multirow{3}{*}{1} & FAR & 6 & 936 & 936 & 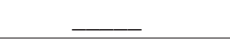 \\
\hline & FDS & 10 & 3.516 & 198 & 1.710 \\
\hline & PAC $(\mathrm{c} /$ recursos FAR $)$ & 12 & 2.700 & 2.280 & 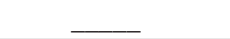 \\
\hline \multicolumn{2}{|c|}{ SUBTOTAL } & 28 & 7.152 & 3.414 & 1.710 \\
\hline 2 & \multirow{2}{*}{ FGTS } & 50 & 7.784 & 7.393 & 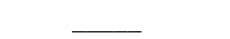 \\
\hline 3 & & 41 & 5.195 & 4.759 & + \\
\hline \multicolumn{2}{|c|}{ SUBTOTAL } & 91 & 12.979 & 12.152 & 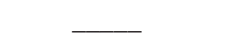 \\
\hline \multicolumn{2}{|c|}{ STOTAL } & 119 & 20.131 & 15.566 & 1.710 \\
\hline
\end{tabular}

FONTE CONSÓRCIO INTERMUNICIPAL DO GRANDE ABC (2OI6)

Programa Minha Casa Minha Vida no ABC -
a produçáo na Faixa 1 e a relaçáo com a ZEIS

Tabela 4 Produção do Programa Minha Casa Minha Vida no ABC - produção total contratada e produção contratada em ZEIs Faixa 1

\begin{tabular}{|l|c|c|c|c|c|}
\hline \multirow{2}{*}{ MUNICÍPIO } & \multicolumn{2}{|c|}{$\begin{array}{r}\text { TOTAL CONTRATADO } \\
\text { FAIXA I }\end{array}$} & \multicolumn{2}{c|}{$\begin{array}{c}\text { TOTAL CONTRATADO } \\
\text { FAIXA I EM ZEIS }\end{array}$} & \multirow{2}{*}{$\begin{array}{c}\text { \% UH CONTRATADAS EM } \\
\text { ZEIS SOBRE O TOTAL DE } \\
\text { UH CONTRATADAS }\end{array}$} \\
\cline { 2 - 5 } & $\begin{array}{c}\text { EMPREEN- } \\
\text { DIMENTOS }\end{array}$ & UH & $\begin{array}{c}\text { EMPREEN- } \\
\text { DIMENTOS }\end{array}$ & UH & \\
\hline Santo André & 11 & 2.438 & 9 & 2.262 & 92,7 \\
\hline Diadema & 9 & 1.582 & 9 & 1.582 & 100 \\
\hline Mauá & 4 & 1.352 & 3 & 1.152 & 85,2 \\
\hline São Bernardo & 4 & 1.780 & 3 & 1.360 & 76,4 \\
\hline TOTAL & $\mathbf{2 8}$ & 7.152 & 24 & $\mathbf{6 . 3 5 6}$ & $\mathbf{8 8 , 8}$ \\
\hline
\end{tabular}

FONTE CONSÓRCIO INTERMUNICIPAL DO GRANDE ABC (20I6)

Com relação à localização nos zoneamentos especiais, da totalidade das 7.152 unidades contratadas na Faixa 1, 6.356 estão localizadas em zoneamentos especiais, o que representa $88,8 \%$ das unidades contratadas. Analisando os municípios, destacam-se Diadema, onde todas as 1.582 unidades contratadas nessa faixa estão localizadas em zoneamentos especiais, e Santo André, onde 92,7\% das 2.438 unidades contratadas nessa faixa estão localizadas nesses zoneamentos. 
Importa destacar também que boa parte da produção em zoneamentos especiais no PMCMV, na Faixa 1, no ABC, está vinculada à produção do PAC em programas e ações de Urbanização, uma vez que a edificação das unidades habitacionais demandadas pelas açóes de Urbanização do PAC são viabilizadas pelo PMCMV. ${ }^{20}$ Em nossa opinião, essa produção relaciona-se com o pioneirismo dos municípios da regiáo em urbanizaçóes de assentamentos precários e na prioridade das administraçóes municipais com relação ao tema, de modo que este contexto converge com o substancial aporte de recursos federais dos últimos anos no âmbito do lançamento do PAC (CIGABC, 2016).

Na tabela 5 a seguir, a produção em zoneamentos especiais está discriminada por município e por modalidade do PMCMV, onde se observa a predominância de empreendimentos destinados à Faixa $1 \mathrm{em}$ tais zoneamentos.

\section{Tabela 5 | Produçáo do Programa Minha Casa Minha Vida no ABC - produçáo contratada em zEIS e modalidades}

\begin{tabular}{|c|c|c|c|}
\hline MUNICÍPIO & ZONEAMENTO & MODALIDADE & UH \\
\hline \multirow{3}{*}{ Santo André } & ZEIS B & Faixa $1 /$ PAC (c/ recursos FAR $)$ & 352 \\
\hline & \multirow{2}{*}{ ZEIS C } & Faixa 1 PAC (c/ recursos FAR) & 880 \\
\hline & & Faixa1/ FDS & 1.030 \\
\hline \multirow{4}{*}{ Diadema } & \multirow{3}{*}{ AEIS 1} & Faixa 1/ FAR & 936 \\
\hline & & Faixa 1/ FDs & 448 \\
\hline & & Faixa 2/ FGTS & 1.089 \\
\hline & AP 2 & Faixa 1/FDS & 198 \\
\hline \multirow{2}{*}{ Mauá } & \multirow{2}{*}{ ZEIS 2} & Faixa 1/PAC (c/ recursos FAR) & 312 \\
\hline & & Faixa1/FDs & 840 \\
\hline \multirow{3}{*}{$\begin{array}{l}\text { Sáo Bernardo do } \\
\text { Campo }\end{array}$} & \multirow{3}{*}{ ZEIS 2} & Faixa 1/PAC (c/ recursos FAR) & 560 \\
\hline & & Faixa 1/FDS & 800 \\
\hline & & Faixa 3/FGTS & 144 \\
\hline \multicolumn{3}{|l|}{ TOTAL } & 7.589 \\
\hline
\end{tabular}

Na figura 1 a seguir, é possível observar que muitos zoneamentos especiais localizam-se em áreas próximas ao manancial, embora este não seja um padrão único. Destacamos os municípios de Santo André e Diadema, onde vários zoneamentos foram gravados em diferentes porçôes dos municípios, e não apenas em suas franjas periféricas. Também, nesses dois municípios, observa-se a variada localização dos empreendimentos do РмСмV nos zoneamentos específicos.

20 Dada a importância da correlação entre urbanização de favelas, PMCMV e PAC/UAP, na região, e a impossibilidade de tratá-la de forma detalhada no escopo deste texto, remetemos o leitor aos seguintes estudos: sobre a dificuldade de articulação entre o PMCMV e PAC no ABC, ver Oliveira e Regino (2014); sobre a operação do PAC no ABC, ver Petrarolli (2015); sobre o panorama da produção do PAC no ABC, ver CIGABC (2016). 
figura I Empreendimentos do Programa Minha Casa Minha Vida Faixa 1 e zeIs de Vazio

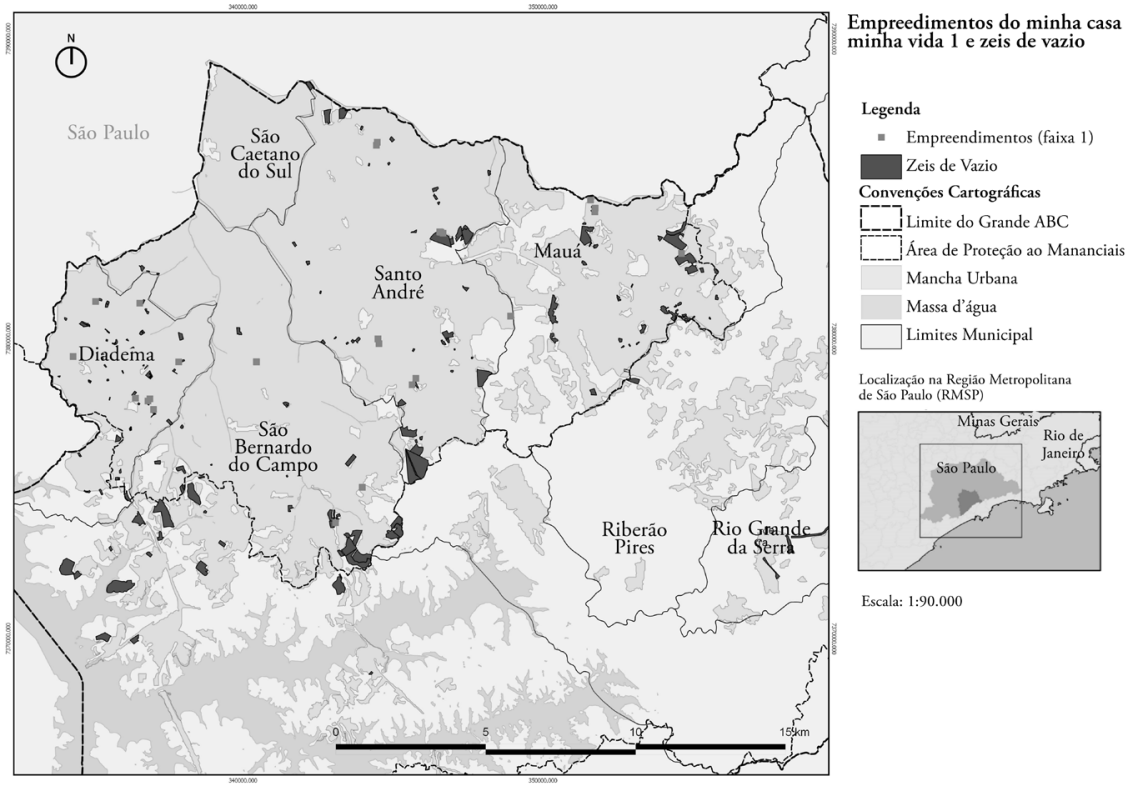

FONTE CONSÓRCIO INTERMUNICIPAL DO GRANDE ABC (2OI6)

São Bernardo do Campo demarcou 47 zeIs de vazios que somam 2.822.733,37 m² (tabela 1), dessas $779.291,95 \mathrm{~m}^{2}$ correspondem a 28 imóveis que foram notificados para PEUC, conforme tabela 6 a seguir. Em tais áreas, há dois empreendimentos do PMCMV contratados na modalidade Entidades, que aguardam o início das obras físicas: Conjunto Residencial Frei Tito, com 500 uh, e Conjunto Residencial Nelson Mandela, com 300 uh, e outros dois empreendimentos estão em fase de elaboração de projeto: o MCMv Cooperativa com previsão de 710 uh e MCMv Montanhão com previsão de 468 unidades. $^{21}$

\section{TABela 6 | Aplicação do Peuc em São Bernardo do Campo}

\begin{tabular}{|l|c|c|c|c|}
\hline $\begin{array}{c}\text { UNIVERSO DE } \\
\text { IMÓVEIS }\end{array}$ & $\begin{array}{c}\text { TOTAL DE } \\
\text { IMÓVEIS }\end{array}$ & ÁREA EM M & $\begin{array}{c}\text { TOTAL DE IMÓVEIS } \\
\text { EM ZEIS 2 }\end{array}$ & ÁREA EM M $^{\mathbf{2}}$ \\
\hline Notificável & 266 & $2.391 .613,78$ & 31 & $814.609,11$ \\
\hline Notificado & 217 & $2.171 .409,75$ & 28 & $779.291,95$ \\
\hline A notificar & 49 & $220.204,03$ & 3 & $35.317,16$ \\
\hline
\end{tabular}

FONTE PREFEITURA MUNICIPAL DE SÃO BERNARDO DO CAMPO. SET/2OI6. ELABORAÇÁO: DÂNIA BRAJATO

21 Nomes provisórios, pois os projetos ainda estão em elaboração. Consórcio Intermunicipal do Grande ABC (2016). 
Após a apresentação da relação da produção do PMCMV, no ABC, com os instrumentos da ZEIS e do PEUC, cabem algumas consideraçôes sobre a inserção urbana, já que a adequada aplicação desses instrumentos tende a incidir diretamente na melhor inserção dos empreendimentos habitacionais em áreas adequadas. Para isso, mobilizamos literatura que analisou o Programa nas seguintes escalas espaciais: região central do Estado de São Paulo, região metropolitana paulistana, regiáo do grande ABC. Esta opção tem a finalidade de nos aproximar do nosso recorte analítico.

Lopes e Shimbo (2015) e Shimbo e Ceron (2014) fizeram a análise conjunta da produção do Programa nas Faixas 1, 2 e 3, na região central do estado de Sáo Paulo, precisamente nos municípios de Ribeirão Preto, São Carlos e Sertãozinho e constataram que "os empreendimentos para Faixa 1, não necessariamente, estão localizados em áreas de extremas periferia e precariedade; e os empreendimentos para Faixas 2 e 3, não necessariamente, estão inseridos em áreas mais consolidadas" (Shimbo \& Ceron, 2014, p. 17). Segundo os autores vários empreendimentos da Faixa 1 localizam-se em áreas urbanas consolidadas em áreas próximas a conjuntos habitacionais públicos, edificados em épocas pregressas.

Marques e Rodrigues (2013) também analisaram o conjunto da produçấo do Programa em suas três faixas para a região metropolitana paulistana, preocupados em medir os padróes de segregaçáo com relação às centralidades principais, aos equipamentos públicos e aos conjuntos habitacionais construídos pelas ações públicas passadas. Como resultado, os autores concluíram que, apesar de a localização dos empreendimentos seguir os padrôes de segregação já estabelecidos na metrópole, esses náo foram intensificados pela produção do Programa. A análise do mapeamento da distribuição dos empreendimentos, aliada às técnicas de geoprocessamento para medir a segregaçáo a partir de dados comparativos de outras produçóes públicas indicou que há empreendimentos da Faixa 1 em localizaçáo periférica mas também em áreas urbanas consolidadas. ${ }^{22}$ Por outro lado, há empreendimentos da Faixa 3 em localizaçóes muito similares aos da Faixa 2, o que sugere que tais localizaçôes não obedecem a uma lógica linear: Faixa 1 em áreas periféricas, e Faixa 3 em áreas centrais.

O estudo realizado por Jesus (2015), específico para a Faixa 1, modalidade Entidades/FDs, na área metropolitana paulistana, demonstrou que muitas áreas em que estão sendo edificados seus empreendimentos são as mesmas onde foram edificados empreendimentos da Faixa 2 do Pмсмv. A pesquisa coordenada por Klink (2015) tomou como referência inicial a evolução das normativas ${ }^{23}$ do Programa no tocante à inserção urbana dos empreendimentos contratados no período analisado para, em seguida, construir metodologia própria para medi-la, analisando os seguintes parâmetros: a) caracterização e localização dos empreendimentos do PMCMV nos municípios, segundo faixas de atendimento (1, 2 e 3 ) e porte do empreendimento (número unidades); b) localização dos empreendimentos na mancha urbana: rede viária e

22 Tal como concluíram Lopes e Shimbo (2015) e Shimbo e Ceron (2014).

23 Medida Provisória no 514, de 01/12/10, convertida na Lei no 12.424, de 16/06/2011; Decreto $n^{\circ}$ 7.499, de 16/06/2011; Portaria Ministério das Cidades de no 465 03/10/2011; Portaria Ministério das Cidades no $168,12 / 04 / 2013$. 
ferroviária, distância aos centros das cidades, rede de centralidades de comércio e serviços, terminais de ônibus e estações de trem, equipamentos de educação, saúde, lazer, assistência social; c) localização dos empreendimentos do PMCMV em relação a aglomerados subnormais, Zonas Especiais de Interesse Social; d) caracterização do entorno em termos de infraestrutura e dados socioeconômicos (renda, escolaridade e raça), a partir dos dados do Censo (Instituto Brasileiro de Geografia e Estatística [IBGE], 2010).

Tais autores mediram a inserção urbana tomando como base os raios de distâncias dos empreendimentos em relação às áreas centrais ou de centralidades regionais municipais, e como conclusão atribuem a boa inserçáo urbana dos empreendimentos à intensa conurbação dos municípios que tende a reduzir as distâncias às principais áreas de centralidade: São Caetano do Sul, Santo André, São Bernardo do Campo, Diadema e Mauá; e à quantidade de serviços, equipamentos públicos e infraestrutura urbana de seus municípios. Os empreendimentos localizados nos zoneamentos especiais foram mapeados sem que os conteúdos fossem analisados detalhadamente.

Nota-se, também, na regiáo do $\mathrm{ABC}$, a mesma dinâmica observada na regiáo central do estado de São Paulo: a não linearidade entre os empreendimentos, de modo que há vários deles na Faixa 3 com localização mais periférica que os da Faixa 1, por outro lado, há empreendimentos Faixa 1 bem localizados, em áreas centrais.

Diniz (2015), por sua vez, aprofundou a análise feita por Klink (2015), construindo metodologia mais apurada para medir a inserção urbana de todos os empreendimentos contratados em todas as faixas, com base na rota de pedestres que permitiu "um maior refinamento e melhor qualificação das características e das deficiências do entorno de cada um dos empreendimentos analisados" (p. 112). Sua justificativa para a construção de um indicador mais refinado foi a de que as diretrizes apresentadas pelas normativas do PMCMV para garantir a inserção urbana dos empreendimentos é bastante permissiva, ademais, tais normativas são obrigatórias apenas para os empreendimentos da Faixa 1 do Programa, razáo pela qual a aplicação do indicador para todos os empreendimentos torna-se relevante, pois, dessa maneira, temos elementos para avaliar toda a produção na região.

Aplicando o indicador por ele criado, dos $112^{24}$ empreendimentos analisados, 49 alcançaram boa inserção urbana, 58 alcançaram satisfatória inserção urbana, três alcançaram insatisfatória inserção urbana, ${ }^{25}$ e dois alcançaram precária inserção urbana. ${ }^{26} \mathrm{O}$ autor atribuiu tais resultados a alguns fatores combinados: boa disponibilidade de infraestrutura, equipamentos e serviços, tanto públicos quanto privados na região, a conurbação dos municípios que, de certa, forma impede a periferização dos conjuntos, e a gravação de ZEIs e sua destinação à produção do PMCMV. Encaminhamos nossos comentários finais lançando mais luz a essa última questão.

24 Atualizando os dados da produçáo do PMCMV no ABC, o estudo realizado pelo CiGABC (2016) chegou em 119 empreendimentos.

25 Residencial Spazio San Thiago - Faixa 2 - 160 uh em São Bernardo do Campo, Conjunto Mauá 1 e 2 - Faixa 1/PAC - 116 e 196 uh em Mauá.

26 Residencial Sonho Meu - Faixa 1/FDs - 200 uh em Mauá e Residencial Ponto Alto - Faixa 1/ PAC - 560 uh em São Bernardo do Campo. 


\section{Consideraçóes finais}

No contexto brasileiro, historicamente, o Estado produziu conjuntos habitacionais em áreas periféricas ou inadequadas, muitas vezes, aumentando a vulnerabilidade socioeconômica de seus beneficiários. O Programa Minha Casa Minha Vida repetiu este padrão. Marques e Rodrigues (2013) lembram, porém, que nenhum programa habitacional anterior construiu conjuntos com localizaçôes adequadas e, por essa razão, não seria razoável supor que o PMCMV o fizesse (p.163). Observa-se que a legislação urbana não foi aplicada de forma a impedir ou inibir esse tipo de padrão de ocupação, ao contrário, foi formulada e aplicada em consonância com os interesses do mercado imobiliário e dos proprietários de terra.

A aprovação do Estatuto da Cidade abriu a perspectiva de um novo rumo para as políticas urbanas, entretanto os instrumentos previstos náo foram aplicados pela maioria dos municípios, ou não alcançaram a finalidade pretendida e relacionada ao ideário da reforma urbana.

Reconhece-se que o tema da inserção urbana e da questão fundiária não foi devidamente valorizado no desenho do PMCMV, mas náo se pode reduzir o papel do município, que pode aprovar e aplicar instrumentos urbanísticos que impossibilitem a produção habitacional em certos setores do município e pode também reservar áreas adequadas para produção de HIs, por meio de aplicação de zoneamento restritivo do tipo zeIs. Também reconhecemos que tais instrumentos têm papel limitado, principalmente, no caso de desenhos de programa como o PMCMV, que tem o setor privado como principal protagonista, e esse, de certa forma, define a localização da produção.

Os municípios da Região do Grande $\mathrm{ABC}$, que possuem limitado estoque de terras vazias e disponíveis para usos urbanos, de forma geral, delimitaram expressivo montante delas como zEIs de vazios, e sua grande maioria é de áreas adequadas e com boa inserçáo urbana. Constatou-se que 88,8\% da produçáo do PMCMV, na Faixa 1, deram-se em áreas demarcadas como zEIs de vazio. A pesquisa realizada por Diniz (2015) apontou que a maioria dos empreendimentos do PMCMV, na região, está localizada em áreas adequadas e, dentre eles, aquele classificado como de melhor inserção urbana é o Conjunto Vitória -Faixa 1/FDS- 228 uh localizado na área central do município de Diadema, gravada como AEIS.

Tais dados confirmam que o município pode desempenhar importante papel por meio da aplicação de instrumentos urbanísticos redistributivos e voltados para ampliar o acesso à terra. Também confirmam que a localização dos empreendimentos e da qualidade da inserção urbanística deles não obedece a uma tendência linear, ou seja, nem todos os empreendimentos destinados à Faixa 1 do Programa (cujo público alvo é a população de menor renda) estão sempre localizados em áreas inadequadas, e nem sempre os empreendimentos da Faixa 3 estâo bem localizados nas cidades.

Dessa forma, Diniz (2015) apontou que o Residencial Spazio San Thiago - Faixa 2- 160 uh, em São Bernardo do Campo, foi classificado como a inserção urbana menos satisfatória dentre todos os empreendimentos pesquisados. Ressaltase que a produção da Faixa 1 foi viabilizada com apoio das prefeituras, por meio de contrapartida, como disponibilização de terrenos, ou execução de obras de 
infraestrutura, e a produção foi articulada com as açôes de urbanização de assentamentos precários. Boa parte das unidades contratadas $(37,75 \%)$ foi destinada a reassentar famílias removidas de favelas em processo de urbanização, e desse total, $84 \%$ encontram-se concluídas no momento de conclusão deste texto. Provavelmente, isso guarda relação direta com o pioneirismo dos municípios da região nas açôes de urbanização de favelas e na prioridade que deram ao tema na última década.

Entretanto, mesmo se tratando de uma região pioneira na aplicação dos instrumentos do Estatuto da Cidade, nota-se que permanece a dificuldade de aplicação de instrumentos como o PEUC. Apesar de três, dentre os oito municípios brasileiros que o estão aplicando, estarem localizados no ABC (Santo André, Diadema e São Bernardo do Campo), apenas em São Bernardo do Campo notam-se avanços, havendo, inclusive, a correspondência entre áreas demarcadas como ZEIs de vazio com os lotes notificados para o PEUC, e a destinação delas à produção de habitação de interesse social, no âmbito do PMCMV.

Outra limitação identificada relaciona-se com a limitada capacidade institucional de alguns municípios, pois, se é verdade que a decisão quanto à localização dos produtos do Programa é, em grande medida, determinada pela atuação das empresas construtoras, é igualmente verdade que a maioria das prefeituras não tem interesse ou capacidade institucional e reguladora para limitar essa açáo. Observouse que, mesmo inseridos dentro de uma mesma região e abrigados pela institucionalidade do Consórcio Intermunicipal do Grande $\mathrm{ABC},{ }^{27}$ é difícil superar as diferenças de capacidade institucional.

O estudo CigABC (2016) indicou que os municípios de Ribeirão Pires e Rio Grande da Serra não previram na legislação urbana conteúdos importantes para exercer o controle urbano mínimo para promover, por exemplo, a regularização fundiária e promover a urbanização de assentamentos precários. Isso nos remete à discussão das escalas e da importância da cooperação entre entes federativos e também ilumina a importância de programas, como o MCMV, estabelecer condicionantes para garantir adequada inserção urbana, ou seja, articular a lógica do financiamento habitacional às estratégias de planejamento e desenvolvimento urbano. Não se pode deixar esta tarefa apenas para os municípios nem atribuir apenas ao município a responsabilidade de tratar os conflitos e disputas territoriais históricas em torno da reprodução do espaço urbano.

Também reconhecemos que náo se pode atribuir apenas às zeIs os resultados alcançados na região. É preciso considerar que os municípios que receberão o maior número de empreendimentos são aqueles com alta densidade e limitado estoque de terras vazias, portanto, o leque de escolhas de áreas não é grande. As características do mercado de terras, grau de urbanização, modelagem de financiamento, entre outros, são fatores que contribuem para definir a localização dos empreendimentos.

27 Atuando no planejamento, articulação e definição de açóes de caráter regional, o Consórcio Intermunicipal do Grande ABC, formado pelos municípios de Santo André, São Bernardo do Campo, São Caetano do Sul, Diadema, Mauá, Ribeirão Pires e Rio Grande da Serra, foi criado em 1990 e, desde 8 de fevereiro de 2010, passou a ser o primeiro consórcio multisetorial de direito público e natureza autárquica do país. Disponível em: http://www.consorcioabc.sp.gov.br/ institucional. Acesso: dez/2016. 
Em que pese a dificuldade de medir o efeito da regulação urbanística, indica-se que ela tem papel fundamental e se sugere a necessidade de realização de estudos e pesquisas que apontem o potencial e limitaçóes dos instrumentos urbanísticos previstos no Estatuto da Cidade, quando aplicados. Importa examinar e debater os arranjos que possibilitam justamente uma produção mais adequada do Programa, considerando, aqui, especificamente, a questão da inserção urbana dos empreendimentos.

\section{Referências bibliográficas}

Arantes, P. \& Fix, M. (2009). Como o Governo Lula pretende resolver o problema da habitação. Alguns comentários sobre o pacote habitacional Minha Casa Minha Vida. Correio da Cidadania, 543. http://www.correiocidadania.com.br

Bentes Sobrinha, M. D., Silva, A.,Tinoco, M., Ferreira, G., Guerra, E., \& Silva, F. (2015). Minha Casa, Minha Vida na Região Metropolitana de Natal: inserção urbana, qualidade do projeto e seus efeitos na segregação socioespacial. Em C. Santo Amore, L. Z. Shimbo, M. B. C. Rufino (orgs.), Minha Casa... E a cidade? Avaliação do Programa Minha Casa Minha Vida em seis estados brasileiros (pp. 323-352). Rio de Janeiro: Letra Capital.

Bonduki, N. (2009). Do "Projeto Moradia” ao "Programa Minha Casa, Minha Vida". Revista Teoria e Debate, (82), 8-14. http://bit.ly/2yfjoSS

Brajato, D. (2015). A efetividade dos instrumentos do Estatuto da Cidade: o caso da aplicaçáo do Parcelamento, Edificação ou Utilização Compulsórios no Município de Maringá (PR). Dissertação. Mestrado em Planejamento e Gestão do Território. São Bernardo do Campo, Universidade Federal do ABC.

Brasil. (2001). Lei no 10.257, de 10 de julho de 2001. Estatuto da Cidade. Regulamenta os Art. 182 e 183 da Constituição Federal, estabelece diretrizes gerais da política urbana e dá outras providências.

Brasil. (2010). Medida Provisória no 514, de 01 de Dezembro de 2010. Altera a Lei no 11.977, de 7 de julho de 2009, que dispóe sobre o Programa Minha Casa, Minha Vida - PMCMv e a regularização fundiária de assentamentos localizados em áreas urbanas, as Leis $\mathrm{n}^{\circ}$ 10.188, de 12 de fevereiro de 2001, 6.015, de 31 de dezembro de 1973, 6.766, de 19 de dezembro de 1979, e 4.591, de 16 de dezembro de 1964, e dá outras providências.

Brasil. (2011). Decreto $n^{\circ} 7.499$, de 16 de Junho de 2011. Regulamenta dispositivos da Lei $\mathrm{n}^{\mathrm{o}}$ 11.977, de 7 de julho de 2009, que dispóe sobre o Programa Minha Casa, Minha Vida e dá outras providências.

Brasil. (2012). Chamada MCTI/CNPq/MCIDADES no 11/2012.

Brasil. (2016). Projeto de Lei ñ 4960, de 31 de Março de 2016. Altera a Lei no 11.977, de 7 de julho de 2009, que dispóe sobre o Programa Minha Casa, Minha Vida - PмCмv e a regularização fundiária de assentamentos localizados em áreas urbanas e dá outras providências. 
Brasil. (2016). Portaria Interministerial no 96 de 30/03/2016. Dispóe sobre as operaçóes com recursos transferidos ao Fundo de Desenvolvimento Social (FDS), contratadas no âmbito do Programa Nacional de Habitação Urbana (PNHU), integrante do Programa Minha Casa, Minha Vida (pmCMv), para os fins que especifica.

Cardoso, A. L (org.). (2013). O Programa Minha Casa Minha Vida e seus efeitos territoriais. Rio de Janeiro: Letra Capital/Observatório das Metrópoles.

Cardoso, A. L., Queiroz e Melo, I. \& Jaenisch, S. T. (2015). A implementação do Programa Minha Casa Minha Vida na Regiáo Metropolitana do Rio de Janeiro: agentes, processos e contradiçốes. Em C. Santo Amore, L. Z. Shimbo, M. B. C. Rufino (orgs.), Minha Casa... E a Cidade? Avaliação do Programa Minha Casa Minha Vida em seis estados brasileiros (pp.73-102). Rio de Janeiro: Letra Capital.

Carvalho. C. S \& Rossbach. A. (orgs.). (2010). O Estatuto da Cidade comentado. São Paulo: Ministério das Cidades / Aliança das Cidades.

Consórcio Intermunicipal do Grande ABC (CIGABC) (2016). Diagnostico Habitacional do Grande $A B C$. https://doi.org/10.13140/rg.2.2.16755.12324

Denaldi, R \& Affonso, A. S. (2012). A efetividade da delimitação de áreas vazias como Zonas Especiais de Interesse Social no município de Santo André: um balanço preliminar. Em R. Denaldi (org.). O desafio de planejar a cidade: politica habitacional e urbana de Santo André SP (1997-2008) (pp. 65-92). São Paulo: Annablume.

Denaldi, R. \& Bruno Filho, F. G. (2012). Parcelamento, Edificação e Utilização Compulsórios: um instrumento (ainda) em construção. Em R. Denaldi (org.), O desafio de planejar a cidade: politica urbana e habitacional de Santo André/sp (1997-2008) (pp. 93-112). São Paulo: Annablume.

Denaldi, R. (coord.). (2015). Parcelamento, edificação ou utilização compulsórios e IPTU progressivo no tempo: regulamentação e aplicação/ Ministério da Justiça, Secretaria de Assuntos Legislativos. Brasília: Ministério da Justiça, Secretaria de Assuntos Legislativos (SAL) / Instituto de Pesquisa Econômica Aplicada (IPEA).

Diadema. (1994). Lei Complementar no 25, de 25 de Janeiro de 1994. Institui o Plano Diretor do Município de Diadema, dispondo sobre diretrizes gerais da política municipal de desenvolvimento urbano, e dá outras providências.

Diniz. J. D. (2015). Análise da inserção urbana nos empreendimentos do Programa Minha Casa Minha Vida no ABC. Periodo 2009-2014. Dissertação. Mestrado em Planejamento e Gestáo do Território. São Bernardo do Campo, Universidade Federal do ABC.

Ferreira, J. S. W. (2012). Produzir casas ou construir cidades? Desafios para um novo Brasil Urbano. São Paulo: Fundação para A Pesquisa Ambiental (Fupam)

Ferreira, J. S. W. (2014). Minha Casa, Minha Vida: notas sobre a responsabilidade coletiva de um desastre urbano. Revista Contraste, 1, 110-119. http://xvienanpur.com.br/ anais/?wpfb_dl=515

Jesus, P. M. (2015). O Programa Minha Casa Minha Vida Entidades no município de São Paulo. Tese Doutorado em Geografia. Departamento de Geografia da Faculdade de Filosofia Letras e Ciências Humanas. São Paulo, Universidade de São Paulo.

Klink, J. (coord.). (2015). Análise da inserção urbanística dos empreendimentos do PMCMV. Em Avaliação do Programa Minha Casa Minha Vida em São Paulo-SP e Grande ABC-SP. Relatório de Pesquisa. 
Krause, C., Balbim, R. \& Lima Neto, V. C. (2013). Minha Casa Minha Vida, Nosso Crescimento: onde fica a política habitacional? Brasília: Instituto de Pesquisa Econômica Aplicada (IPEA). (Texto para discussão 1853).

Lobo Jr, L. G. (2014). O urbanismo progressista e a produção do espaço urbano: limites e potencialidades das AEIS em Diadema. Dissertação. Mestrado em Planejamento e Gestão do Território. São Bernardo do Campo, Universidade Federal do ABC.

Lopes, J. M. A. \& Shimbo, L. (2015). Projeto e produção da habitação na regiáo central do estado de São Paulo: condiçôes e contradiçóes do pmcmv. Em C. Santo Amore, L. Z. Shimbo, M. B. C. Rufino (orgs.), Minha Casa... E a Cidade? Avaliação do Programa Minha Casa Minha Vida em seis estados brasileiros (pp. 229-254). Rio de Janeiro: Letra Capital.

Malvese. S.T. (2014). Zonas Especiais de Interesse Social? ZEIS de vazios, e a função social da propriedade na Região DO ABC. Dissertação. Mestrado em Planejamento e Gestão do Território. Sáo Bernardo do Campo, Universidade Federal do ABC.

Maricato, E. (2009). O "Minha Casa” é um avanço, mas segregação urbana fica intocada. Entrevista concedida à Agência Carta Maior em Maio de 2009.

Marques, E. \& Rodrigues, L. (2013). O Programa Minha Casa Minha Vida na metrópole paulistana. Revista Brasileira de Estudos Urbanos e Regionais, 15(2), 159-177. http:// bit.ly/2g6YeM1

Mauá. (2007). Lei no 4.153, de 26 de março de 2007. Aprova o Plano Diretor do Município de Mauá.

Oliveira, N. Apa \& Regino, T. de M. (2014). Urbanização de assentamentos precários e integração de investimentos municipais com o PAC e o PMCMV: o caso de São Bernardo. Em Anais do I Seminário Nacional de Urbanização de Favelas (URBFAVELAS).

Pequeno, R. \& Rosa, S. (2015). Inserção urbana e segregação espacial: análise do Programa Minha Casa Minha Vida em Fortaleza. Em C. Santo Amore, L. Z. Shimbo, M. B. C. Rufino (orgs.) Minha Casa... E a Cidade? Avaliação do Programa Minha Casa Minha Vida em seis estados brasileiros (pp. 131-164). Rio de Janeiro: Letra Capital..

Petrarolli, J. (2015) O tempo nas urbanizaçōes de favelas: contratação e execução de obras do PAC no Grande $A B C$. Dissertação. Mestrado em Planejamento e Gestão do Território. São Bernardo do Campo, Universidade Federal do aвC.

Reali, M \& Alli, S. (2010). A cidade de Diadema e o Estatuto da Cidade. Em C. Santos Carvalho \& A. Rossbach (orgs.), O Estatuto da Cidade comentado. São Paulo: Ministério das Cidades / Aliança das Cidades.

Rizek, C. S., Santo Amore, C., Camargo, C., Castro A. Q., Pereira, R. B., Rodrigues, D. P. \& Pereira, M. B. (2015). Viver na cidade, fazer cidade, esperar cidade. Inserçóes urbanas e o PMCMv-Entidades: incursóes etnográficas. Em C. Santo Amore, L. Z. Shimbo, M.

B. C. Rufino (orgs.), Minha Casa... E a Cidade? Avaliação do Programa Minha Casa Minha Vida em seis estados brasileiros (pp. 289-322). Rio de Janeiro: Letra Capital.

Rolnik, R. \& Nakano, K. (2009). As armadilhas do pacote habitacional. Le Monde Diplomatique Brasil, 2(20), 5 de março de 2009. http://diplomatique.org.br/as-armadilhas-dopacote-habitacional/

Rolnik, R. (coord.). (2010). Como produzir moradia bem localizada com recursos do Programa Minha Casa Minha Vida?: Implementando os instrumentos do Estatuto da Cidade! Brasília: Ministério das Cidades. Cartilha. 
Rolnik, R. (2012). 10 anos do Estatuto da Cidade: das lutas pela Reforma Urbana às cidades da Copa do Mundo. Em A. C. T. Ribeiro, L. F. Vaz, M. L. P. Silva, (orgs.), Quem planeja o território? Atores, arenas e estratégias (pp. 87-104). Rio de Janeiro: Letra Capital/ ANpur (Associação Nacional de Pós-graduação e Pesquisa em Planejamento Urbano e Regional)

Rolnik, R (org.). (2014). Ferramentas para avaliação da inserção urbana dos empreendimentos do $M C M V$. Relatório de Pesquisa. Faculdade de Arquitetura e Urbanismo, Universidade de São Paulo.

Rolnik, R., Pereira, A.; Lopes, A., Moreira, F., Borrelli, J., Vannuchi, L., Royer, L., Rossi, L., Iacovini, R. \& Nissida, V. (2015). Inserçâo urbana no PMCMV e a efetivação do direito à moradia adequada: uma avaliação de sete empreendimentos no estado de São Paulo. Em C. Santo Amore, L. Z. Shimbo, M. B. C. Rufino (orgs.) Minha Casa... E a Cidade? Avaliação do Programa Minha Casa Minha Vida em seis estados brasileiros (pp. 391416). Rio de Janeiro: Letra Capital.

Rufino, M. B. (2015). Um olhar sobre a produção do PмCMv a partir de eixos analíticos. Em C. Santo Amore, L. Z. Shimbo, M. B. C. Rufino (orgs.), Minha Casa... E a Cidade? Avaliação do Programa Minha Casa Minha Vida em seis estados brasileiros (pp. 51-72). Rio de Janeiro: Letra Capital..

Rufino, M. B., Uemura, M. M., Menegon, N., Klintowitz, D. C., Ferreira, A., Frignani, C. \& Barreto, F (2015). A produção do Programa PMCMv na Baixada Santista: habitação de interesse social ou negócio imobiliário? Em C. Santo Amore, L. Z. Shimbo, M. B. C. Rufino (orgs.), Minha Casa... E a Cidade? Avaliação do Programa Minha Casa Minha Vida em seis estados brasileiros (pp.103-132). Rio de Janeiro: Letra Capital.

Santo Amore, C., Shimbo, L. Z. \& Rufino, M. B. C. (orgs.) (2015). Minha Casa ... E a Cidade? Avaliação do Programa Minha Casa Minha Vida em seis estados brasileiros. Rio de Janeiro: Letra Capital.

Santo André. (1991). Lei no 6.864, de 21 de Dezembro de 1991. Institui as Áreas Especiais de Interesse Social - AEIs e dá outras providências.

Santos Jr, O. A \& Montandon, D. T. (orgs.) (2011). Os planos diretores pós-estatuto da cidade: balanço crítico e perspectivas. Rio de Janeiro: Letra Capital / Observatório das Metrópoles, Instituto de Pesquisa e Planejamento Urbano e Regional da Universidade Federal do Rio de Janeiro (IPPUR/UfrJ).

São Bernardo do Campo. (2006). Lei no 5.593, de 5 de Outubro de 2006. Aprova o Plano Diretor do município de São Bernardo do Campo e dá outras providências.

Shimbo, L. \& Ceron, L. (2014). Produção do pmcmv na Regiāo Central do Estado de São Paulo: um híbrido entre ocupação nas periferias e em áreas consolidadas. Em III Encontro da Associação Nacional de Pesquisa e Pós-graduação em Arquitetura e Urbanismo. Arquitetura, cidade e projeto: uma construção coletiva. Anais. Universidade Presbiteriana Mackenzie (UPM): São Paulo; Pontifícia Universidade Católica de Campinas (PUCCAMP): Campinas.

Souza, C.V., Bruno Filho, F., Bossi, W. \& Gazola, M. (2013). Novas perspectivas para o Parcelamento, Edificação e Utilização Compulsórios (peUc): o caso de São Bernardo do Campo (sp). Em VII Congresso Brasileiro de Direito Urbanistico. Anais. Pontificia Universidade Católica de São Paulo (puc-São Paulo). 